\title{
Intergenerational Conflict or Solidarity in Hong Kong? A Survey of Public Attitudes Toward Social Spending
}

\author{
Alfred M. Wu ${ }^{1}$ (D) Kee-Lee $\mathrm{Chou}^{2}$ \\ Accepted: 1 January 2021 / Published online: 31 May 2021 \\ (c) The Author(s) 2021, corrected publication 2021
}

\begin{abstract}
This study aims to investigate age-related differences in social spending preference in an Asian context, drawing on a random survey of more than 1000 adults in Hong Kong in 2013. Contrary to popular belief, older adults in Hong Kong hold a negative view toward welfare spending, especially when it is directed toward the poor population. In contrast, descriptive statistics reveal that younger people tend to support increased spending on welfare assistance. The findings in this study provide evidence that reciprocity and solidarity in intergenerational relationships are present in Hong Kong. This demonstrates the nature of shifting social values held by different generations in a dynamic and demographically pressured Asian context. Amidst rising intergenerational conflict in different contexts in Asia, this study has profound implications for policymaking.
\end{abstract}

Keywords Social policy $\cdot$ Public attitude $\cdot$ Poverty $\cdot$ Aging $\cdot$ Hong Kong $\cdot$ Asia

\section{Introduction}

Distributive and redistributive policy is at the forefront of policy debates in many developed economies. Hong Kong is no exception to this, as a rapidly aging population has sparked more debate about whether the government should spend more to protect underserved elderly residents. The negative effects of an aging population are also exacerbated by potential external shocks (for example, the economic slowdown of Hong Kong's most vital economic partner, Mainland China, could create vulnerabilities for the territory). In good economic times, people benefit from a buoyant economy. In hard times, individual and community resilience is vital to maintaining a well-functioning society. Development policy suggests that economic shocks can be counteracted with social investments into education, healthcare, and other forms of basic social care (Kulig et al. 2013). Hong Kong

Alfred M. Wu

wumuluan@gmail.com

Kee-Lee Chou

klchou@eduhk.hk

1 Lee Kuan Yew School of Public Policy, National University of Singapore, Singapore

2 Department of Asian \& Policy Studies, The Education University of Hong Kong, Hong Kong, People's Republic of China 
can benefit from increased expenditure into these areas, by providing assistance to uplift the most vulnerable segments of society and maintain economic resilience. However, little is known about the public preferences for distributive and redistributive policy among Hong Kong residents.

This study investigates public attitudes toward redistributive programs, with an emphasis on how preferences toward social spending differ according to age. In a fast-aging society, it is largely assumed that self-interest will motivate older people to support increased social spending on areas that benefit them directly, such as retirement (Goerres and Tepe 2010). Further, they may oppose spending on education, which is a policy area that has a direct effect on children and young adults. However, intergenerational solidarity and reciprocity have provided evidence against such assumptions, demonstrating that people's preferences are not motivated strictly by self-interest. We ask the questions: whether age plays a role in affecting public support for distributive and redistributive programs and how it makes an impact on different social policy realms.

Public spending on social programs comprises a large part of the government budget in many developed economies. In terms of the percentage of public spending, the total budget spent on social policy in Hong Kong has been lower than the OECD (Organization for Economic Co-operation and Development) average. The Hong Kong SAR government claims that it has attempted to increase social spending in recent years. Disagreement in this area has not been reduced. For example, public spending on education latterly has been massive, representing 20.4\% of total government expenditure in the fiscal year 2018-19 in Hong Kong. ${ }^{1}$ Against this backdrop of substantial spending on education, the criticism of the education system in Hong Kong is nonetheless pronounced. For retirement income protection $^{2}$ (available in most developed and developing economies) (OECD 1998), it is still in debate (Commission on Poverty 2015). Intriguingly, 30\% of government recurrent spending went to older people in Hong Kong (mostly toward the CSSA), which enables poor people to cover their living costs.

In the literature related to age-related differences in public spending, age proves to be an important explanatory variable. However, age is generally only used as a control variable instead of an independent variable (Goerres and Vanhuysse, 2012). In developed democracies, the age factor is crucial in the discussion of voting behaviors and welfare programs. A pro-elderly spending bias is argued to be dominant in many countries (Goerres and Vanhuysse 2012). Nevertheless, limited research has been conducted as to whether age impacts public attitudes toward social spending (a few exceptions include Goerres and Tepe 2010), particularly in the Asian context.

Population aging characterizes the trend in Hong Kong. Based on the definition by the World Health Organization (WHO), the year 2013 saw Hong Kong become an aged society (Chan and Liang 2013). In many Western democracies, the period in which the percentage of the elderly (aged 60 years and above) doubled from 7 to $14 \%$ was relatively long. For example, the period was approximately 50 years for Australia and New Zealand. The same process took a shorter period in Hong Kong: it took only 25 years for the proportion of older persons in Hong Kong to increase from $7.1 \%$ in 1970 to $13.9 \%$ in 1995

\footnotetext{
1 See Government Expenditure on Education of the Hong Kong SAR Government. http://www.edb.gov.hk/ en/about-edb/publications-stat/figures/gov-expenditure.html and https://www.legco.gov.hk/research-publi cations/english/1718rb02-the-2018-2019-budget-20180412-e.pdf.

2 Chou et.al. (2015) note, workers in Hong Kong hold a negative view toward the Mandatory Provident Fund (MPF) scheme, a compulsory saving scheme for the retirement of Hong Kong residents (coming into operation on 1 December, 2000).
} 
(see Report on Ageing and Health in the Western Pacific Region by the WHO, 2014). ${ }^{3}$ According to the United Nations, by 2050 , Hong Kong will be one of ten economies with the highest old-age dependency ratio $(65+/ 20-64) .{ }^{4}$ Perhaps more importantly, compared to other Asian countries, the labor force participation of older adults (aged 60 years and above) is comparatively low in Hong Kong. ${ }^{5}$ These demographic conditions will have profound implications for government spending on social programs, particularly those related to older people. ${ }^{6}$

Income inequality also fundamentally defines Hong Kong's socioeconomic conditions and public attitudes toward social spending. It is one of the most unequal societies in Asia. According to the United Nations Development Program (UNDP 2010), Hong Kong ranked highest for income inequality out of 32 countries (economies) with very high human development. In 2013, the city housed 1.3 million poor people out of a total population of 7 million, based on the poverty line set by the government (50\% of the median monthly household income before tax and welfare transfers) (South China Morning Post, 28 September 2013). ${ }^{7}$ Further, the city is home to an increasing number of super-rich individuals, with only 45 billionaires holding wealth amounting to $\$ 214$ billion - which was nearly $80 \%$ of Hong Kong's GDP in 2013 (Forbes.com, 30 September 2014). ${ }^{8}$ Based on the data from 1981 to 2001, Chou and Chow (2005) note that income inequality had been most pronounced among the elderly population, although their income situations generally improved.

Due to these changing demographic characteristics and socioeconomic conditions, we investigated age differences in regard to public attitudes toward social spending in Hong Kong. We assume that age plays a role in affecting public attitudes toward social policy, as public investment in education, healthcare, and retirement income protection have different impacts across age groups. Both the self-interest and social values hypotheses on public spending preferences hold true.

Using a unique random survey conducted in Hong Kong in 2013, this study is a first attempt to investigate age-related differences in public spending preference in a non-Western context. This study is expected to make some contributions to research and practice. First, it was an individual-level survey in a dynamic and changing Asian society. The bulk of the existing research comprises multi-country studies, especially among OECD countries. A national-level study of public attitudes toward redistribution reaps benefits. Nevertheless, we argue that a micro-level, individual-level public opinion study on distribution and redistribution may generate greater insight into the issue and shed light on policymaking in this area. Second, the study was conducted in a unique and significant context. Hong Kong has a highly free market, a rapidly aging population, growing income inequality, and

\footnotetext{
3 Ageing and Health in the Western Pacific Region. http://www.wpro.who.int/topics/ageing/ageing_fs.pdf.

4 The old-age dependency ratio will be $71 \%$ in Hong Kong. https://www.un.org/en/development/desa/popul ation/publications/pdf/ageing/WorldPopulationAgeing2019-Highlights.pdf.

${ }^{5}$ Research Office at the Legislative Council Secretariat in Hong Kong, 28 October 2016. https://www.legco.gov.hk/research-publications/english/1617issh05-elderly-employment-20161028-e.pdf.

6 A recent study suggested that older adults who migrated from Mainland China to Hong Kong were more likely to be poor after controlling for different demographic factors (Chan and Chou 2016).

7 It hit one out of five being poor by late 2017. See Poverty in Hong Kong hits record high, with 1 in 5 people considered poor, 18 November 2017. http://www.scmp.com/news/hong-kong/community/article/ 2120366/poverty-hong-kong-hits-7-year-high-one-five-people. Poverty is more severe among older people in Hong Kong (see Chan and Chou 2018; Lee and Chou 2016).

8 Beyond the Umbrella Movement: Hong Kong's Struggle with Inequality In 8 Charts. http://www.forbes. com/sites/liyanchen/2014/10/08/beyond-the-umbrella-revolution-hong-kongs-struggle-with-inequality-in-8charts/\#23f5727f50b6.
} 
many redistributive challenges. This study offers some insights into public attitudes toward social spending in Asia but also in other countries around the world.

The main body of the article begins with a discussion of the literature in this area and proposes theoretical hypotheses informing the empirical analysis. The second section reports the methodology and findings based on descriptive data and logistic regression models. The third section discusses the empirical results and presents relevant explanations. The final section concludes with policy implications.

\section{Literature Review: Self-Interest Versus Social Values Hypotheses}

The literature on public attitudes toward social spending is dominated by two main hypotheses: the self-interest hypothesis and the social values hypothesis. There are two main explanations. The self-interest hypothesis, associated with an individual's personal circumstances, assumes that those who are likely to receive or are currently receiving welfare benefits will support greater distribution and redistribution. Contrastingly, those who are unlikely to benefit from welfare programs tend to disapprove of them because they receive no direct tangible benefits, despite paying for them through taxes. For example, the unemployed are more likely to have positive attitudes toward welfare provision related to unemployment (Jæger 2006). Evidence suggests that an individual's position in the labor market affects the person's public attitudes toward welfare programs substantially (Svallfors 1997). The self-interest hypothesis relates both to the real situation of being vulnerable and perceived vulnerability. Those who view themselves as part of a lower social class are inclined to support greater redistribution from the rich to the poor, regardless of whether they actually belong to a lower social class in reality (Svallfors 2004). It does not matter whether one actually belongs to a lower social class. In sum, the above assumption is in line with the premise that human behavior is primarily driven by self-interest (Funk 2000).

In contrast to the self-interest hypothesis, the social values hypothesis supposes that public attitudes toward social spending may not hinge on personal interests. Funk (2000) noted that "Values are commonly defined as general and enduring beliefs that provide standards or normative prescriptions by which people evaluate themselves, others, issues, and events" (p. 41). First, this means that social values are more stable and enduring than personal interests, while personal circumstances may change quickly, and therefore one's own interests can be volatile. Nevertheless, social values, once formed, survive for a longer period and have a continuing impact. Second, social values may be independent of personal circumstances and reflect a more complex pattern of social beliefs. For example, in contrast to the concept of the welfare state, economic individualism assumes that individual wellbeing should be an outcome of personal efforts. Individualism holds that the individual must take full responsibility for his or her own welfare instead of receiving state support based on collective contributions (Blekesaune and Quadagno 2003). The welfare state nonetheless violates certain principles of aligning personal benefits with individual efforts.

Further, some believe that people are marginalized simply due to their laziness or lack of willpower, and thus believe they are undeserving of social assistance. However, this view may be misinformed. As structural problems such as intergenerational poverty cause the marginalization of certain groups, it is a societal responsibility to address these inequalities. Therefore, people must sacrifice their own self-interests to maximize the whole benefit of society, by uplifting the most vulnerable from poverty (Funk 2000). The welfare state concept is aligned with humanitarianism, which explains public support for social 
spending in a variety of contexts (Feldman and Steenbergen 2001). For example, a country dominated by economic individualism may embrace the characteristics of a welfare state for certain reasons. A liberal welfare state might also not have full support from the people, as some favour certain types of redistribution (such as spending on education), but not others (Dorey 2010; McCall and Kenworrthy 2009). In addition, existing social policy may affect social values. A ratchet effect on social spending has been well documented in many countries (Menz 2015). Thus, people will become accommodated to the existence of longstanding welfare programs and end up supporting them more over the long-term.

The social values hypothesis has recently received increasing attention. It suggests that certain factors, such as social values or ideologies, may affect people's perceptions of distributive and redistributive programs. In alignment with this hypothesis, people will support or oppose welfare independent of their current socioeconomic situation. For example, those that are well off may still support social spending due to their ideological beliefs, while those that are economically disadvantaged may oppose welfare due to their social values even if it would benefit them. Empirical evidence also supports the social values hypothesis (Fong 2001). People who view poverty as a structural, societal problem versus an issue that is self-induced by the poor are more likely to support welfare regardless of their economic situation.

The self-interest hypothesis does not always conflict with the social values hypothesis. With regard to the relationship between age and support for public distribution, the two hypotheses, self-interest and social values, appear to concur to some extent, but for different reasons. Busemeyer et al. (2009, p. 196) pointed out that "one's position in the life cycle" affects attitudes toward distribution. The self-interest hypothesis posits that as people become older, especially near retirement, they tend to be less competitive in the labor market. They are thus likely to care more about government assistance. Some research has documented that the elderly tend to support programs benefiting seniors (such as old-age pensions and elderly care). At the same time, young people are inclined to support programs from which they benefit directly (such as public investment in education) (see Busemeyer et al. 2009). According to the social values hypothesis, as people age, they tend to become more sophisticated. Therefore, people will understand different scenarios in the life cycle and think considerately for other people. Even older people in good financial situations support more government assistance toward some in marginalized situations.

Family solidarity plays a critical role in affecting public attitudes toward welfare programs, as it causes people to empathize with people of different ages (Goerres and Tepe 2010). This solidarity derives from the experience and feeling of being part of a family. For example, grandparents might support spending on early education because they want their grandchildren to have the opportunity to go to a quality school. As social scientists have long acknowledged, the family has a great impact on societal, economic, and political behaviors (Goerres and Tepe 2010). Within a familial context, individual behaviors may be more altruistic rather than self-interested (Becker 1981; Goerres and Tepe 2010). Therefore, due to family solidarity, individuals may support redistributive programs, which are unlikely to benefit them in the near future. For example, in a study of Norwegian public opinion, Daatland et al. (2012) found an intergenerational exchange: the majority of the youngest (77\%) supported elderly care while $72 \%$ of the elderly also supported spending on school programs. Similarly, some studies have discussed older people's altruistic attitudes; the elderly even support some programs that offer little benefit to older adults but are beneficial for other age groups. For example, Goerres and Tepe (2010) used the case 
of public childcare, which is generally not relevant to older people's needs, to confirm the social values hypothesis among the elderly. ${ }^{9}$

In summary, the age-related differences in public spending preferences are very nuanced and complex. In a world increasingly shaped by the effects of globalisation, post-materialist values, and rising pressure for government assistance, public preferences are complicated by a variety of trends. On the surface, people may support welfare programs that are beneficial toward themselves immediately or in the near future. Older people will lend support to retirement income protection while young people may favor greater public spending on education. Nevertheless, family solidarity may influence older people to support increased spending on public education and young people to support retirement protection. Furthermore, in some contexts, different generations may adhere to significantly different social values or ideologies relating to distribution and redistribution, thereby rendering the situation complex.

\section{Methodology}

\subsection{Data Collection}

We conducted a random telephone survey in Hong Kong in March 2013. ${ }^{10}$ The participants fulfilled the inclusion criteria: (1) adults aged 18 and above; (2) Hong Kong residents; and (3) Cantonese speakers. ${ }^{11}$ All interviews were conducted anonymously with the quality assurance mechanism in place. The sample size was 1032, and the effective response rate was $68.0 \%$. Due to missing values in the variables used in this study, the sample size for different models may be smaller than 1032 .

\subsection{Measures}

The survey included a number of questions on public attitudes toward distributive and redistributive spending in eight social policy areas: welfare, assistance to the poor, public health services, education, assistance to children living in poverty facilitating better access to education, the comprehensive social security assistance scheme, retirement income protection, and public housing. The items on spending read: "Listed below are various areas of government spending. Please show whether you would like to see more or less government spending in each area. Remember that if you say 'much more,' a tax increase may be required to pay for it. More or less government spending on ..." The options provided were: "much more," "somewhat more," "the same as now," "somewhat less," "much less," "not sure," and "refuse to answer." Following a recent study (Busemeyer et al. 2009), we combined these five categories into three, thus yielding a three-step ordinal variable ranging from "spending less or much less" and "the same as now," to "spending more or much more." We assumed that the differences between reporting "much more" and "more" and between "much less" and "less" are not important to our research questions. We counted the responses of "not sure" and "refuse to answer" as missing values in our data analyses.

\footnotetext{
${ }^{9}$ It should be noted that support for public childcare is context-dependent (see Goerres and Tepe 2010).

${ }^{10}$ On the survey method, please refer to $\mathrm{Wu}$ and Chou (2017).

${ }^{11}$ Cantonese is a dominant language in Hong Kong.
} 
Table 1 Distribution of combined categories of age and labor force status $(\mathrm{N}=1,024)$

\begin{tabular}{lllll}
\hline & Age $<30$ & $30-59$ & $60+$ & Total \\
\hline $\begin{array}{l}\text { Labor force status } \\
\text { In work }\end{array}$ & $9.18 \%(94)$ & $33.50 \%(343)$ & $6.35 \%(65)$ & $49.02 \%(502)$ \\
$\begin{array}{l}\text { Out of labor force (unem- } \\
\quad \text { ployed, housewife/househus- }\end{array}$ & $0.78 \%(8)$ & $11.82 \%(121)$ & $5.96 \%(61)$ & $18.55 \%(190)$ \\
$\quad$ band) & & & \\
$\quad \begin{array}{l}\text { In education } \\
\text { Retired }\end{array}$ & $6.45 \%(66)$ & $0.10 \%(1)$ & $0.00 \%(0)$ & $6.54 \%(67)$ \\
Total & $0.00 \%(0)$ & $3.42 \%(35)$ & $22.46 \%(230)$ & $25.88 \%(265)$ \\
\hline
\end{tabular}

Number of observations in parentheses

We integrated two variables - respondents' age and employment status-into one nominal variable with six categories. By combining age and labor market status into one nominal variable, we ensured that the estimates of their impact on dependent variables would be efficient in a statistical sense. In the meantime, we acknowledge the limitation of this treatment given that the results would not separate the influence of age from that of employment status. $^{12}$

Age was divided into three groups: 18-30 years old, 30-59 years old, and 60 years and older. Labor market status was categorized into four classes: in work, out of the labor force (unemployed, housewife/househusband), in school, and retired. There are 12 values for the combined nominal variable of age, but some of them were negligible because they rarely occurred and therefore were merged with adjacent categories: $0.78 \%$ of these were younger than 30 and out of the labor force, $0 \%$ were reported younger than 30 and retired, $0.10 \%$ were middle-aged and in education, and $0 \%$ were older than 60 and in school. Two values (the first and the third) were merged with other categories. More importantly, we included those who were older than 60 and out of the labor force in the retired and older adult category to reflect the meaning of retirement in the Hong Kong context.

This study included six categories in the combined variable of age and labor force status: younger than 30 and in work, younger than 30 and in education, 30-59 and in work (reference group), 30-59 and out of the labor force, older than 60 and in work, and older than 60 and retired (see Table 1). These categories not only captured all the meaningful combinations of age groups and positions in the labor market, but may also solve the problem of collinearity (Busemeyer et al. 2009).

Besides age and labor force status, we also included three groups of variables. The variables of the self-interest hypothesis included perceived vulnerability to a worsening financial situation, being of a lower social class, and the number of children in a family. Perceptions of vulnerability to a reduction in quality of life were assessed by asking the respondents, "Do you think that in the next 12 months, you and your family will be better off than today or worse off?" Responses were measured using a 3-point scale ("better" $=0$, "no difference" $=1$, and "worse" $=2$ ). Self-rated social class was also included as a subjective indicator of the financial situation of a household. The respondents were

\footnotetext{
12 Supplementary analyses were conducted to observe the age differences in social spending preferences when separating age and employment status. The separation of age and employment status also yielded similar results with regard to the impact of age.
} 
asked to indicate which social class their family belonged to, choosing from the options of "upper class," "upper-middle class," "middle class," "lower-middle class," and "lower class." One binary variable was recoded as an indicator of lower class compared with all other response categories. The number of children was grouped into four categories $(0=0$, $1=1,2=2$, and $3=3$ or more).

The variables related to the social values hypothesis included the perceived causes of income inequality, the magnitude of income inequality, and the perceived causes of poverty. The first was measured using the item "Inequality continues to exist because it benefits the rich and the powerful," and the second using the item "Differences in income in Hong Kong are too large." The respondents rated both items using a 5-point Likert-type scale ranging from $1=$ "strongly disagree" to $5=$ "strongly agree." Perceptions of the causes of poverty were assessed using one item in which the respondents were asked "Why are there poor people in Hong Kong? Here are four possible reasons: bad luck, laziness or lack of willpower, injustice in society, and modern social development. Which reason do you consider to be the most important? And which do you consider to be the second-most important?" The order in which the four reasons were presented was randomized. In our analyses, we recoded responses to this item into three dummy variables depending on which reason was selected as most important: (1) bad luck, (2) laziness or lack of willpower, and (3) injustice in society. Finally, the last set of variables covered basic demographic characteristics, namely, gender, education level, and marital status.

\subsection{Analyses and Empirical Results}

We conducted the statistical analyses and derived the following findings. First, the frequency distribution of public attitudes to social spending in eight policy areas is presented in the following section. Second, the descriptive statistics of all independent variables used in this study were obtained. Third, the logistic regression models were performed to assess the association of the combined age and labor force status variable with spending preferences in the eight policy areas. Finally, we repeated the logistic regression analyses by including self-interest, social values, and socio-demographic variables.

\subsection{Descriptive Statistics}

Public support for government intervention is high in Hong Kong, as many assume that a liberal type of welfare system in Hong Kong would not provide proper support for social spending. As shown in Table 2, there was great support from the respondents to spend more money in the majority of the social policy areas under study: $64.8 \%$ of the respondents agreed to spend more on welfare in general. In particular, a large majority $(71.4 \%$ of the respondents) supported greater spending on assistance to the poor. Assistance for poor children received even higher support (78.2\%). Public support for retirement income protection was also very high $(76.7 \%)$. On public health services, $82.6 \%$ of respondents supported increased spending, indicating that this particular welfare program was popular in Hong Kong. Higher spending on education was supported by $77.2 \%$ of respondents. Public housing received the greatest support from the respondents, as $83.7 \%$ expressed agreement with spending more in this area. Nevertheless, the Comprehensive Social Security 
Table 2 Frequency distribution of public attitudes toward social spending in eight policy areas

\begin{tabular}{lrrll}
\hline Attitudes toward redistributive spending & $\mathrm{N}$ & $\begin{array}{l}\text { Less Spend- } \\
\text { ing (\%) }\end{array}$ & Same as now (\%) & $\begin{array}{l}\text { More } \\
\text { spending } \\
(\%)\end{array}$ \\
\hline Welfare & 980 & 9.3 & 25.9 & 64.8 \\
Assistance to the poor & 972 & 5.5 & 23.1 & 71.4 \\
Public health services & 1016 & 1.2 & 16.2 & 82.6 \\
Education & 1000 & 2.7 & 20.1 & 77.2 \\
Assistance to poor children & 981 & 3.9 & 17.9 & 78.2 \\
CSSA & 950 & 23.6 & 47.6 & 28.8 \\
Retirement income protection & 957 & 3.1 & 20.2 & 76.7 \\
Public housing & 1005 & 3.3 & 13.0 & 83.7 \\
\hline
\end{tabular}

Assistance (CSSA) Scheme was not as popular as others: $47.6 \%$ of the respondents thought that spending on CSSA should remain the same. ${ }^{13}$

In summary, the respondents of Hong Kong supported greater expenditure on social spending even when the questions indicated that if government spending increased, residents would likely need to pay more taxes. Only the CSSA drew less favorable views.

Table 3 suggests that age-related differences exist in some areas in the frequency distribution of public attitudes toward social spending. First, younger people tended to support more spending on welfare and assistance to the poor: $72.3 \%$ of the respondents aged under 30 preferred more spending on these policy areas whilst $56.9 \%$ of the elderly expressed the same preference. Second, older adults tended to support more spending on public health services and education: $80.4 \%$ of the respondents aged 60 and above favored more spending on education, compared with only $64.1 \%$ of young people (aged 30 years or below). Third, with regard to retirement income protection, those aged above 30 generally shared the same preference - to spend more in this area-while the preference for more spending on younger people tended to be less pronounced.

In alignment with the social values hypothesis, descriptive statistics (Table 4) indicated that many Hong Kong people care about social justice. For example, on the perceived causes of poverty, bad luck was ranked lowest. $4.7 \%$ of the respondents expressed the opinion that bad luck resulted in poverty. $31.8 \%$ of the respondents perceived laziness as a cause of poverty. Social development, ranked the highest, was perceived as a great contributor to poverty in Hong Kong (about $35.4 \%$ of the respondents chose this cause). Treating individual and structural causes of poverty separately, we found that the majority of the respondents $(63.5 \%)$ considered poverty to be a result of injustice or social development, which goes beyond individual factors leading to poverty. Perceived causes of income inequality also show a modest to high level with an average score of 3.65 on the 5 -point Likert-type scale ranging from $1=$ "strongly disagree" to $5=$ "strongly agree." The

\footnotetext{
13 The Comprehensive Social Security Assistance Scheme intends to provide cash-based support to those people who cannot meet basic needs based on their income. Some Hong Kong people stereotype CSSA recipients as lazy and lacking willpower (Wong and Lou 2010; Yang et al. 2020). A large number of CSSA recipients are aged poor as they do not have retirement protection (see Chui and Ko 2010; Tang 2000).
} 


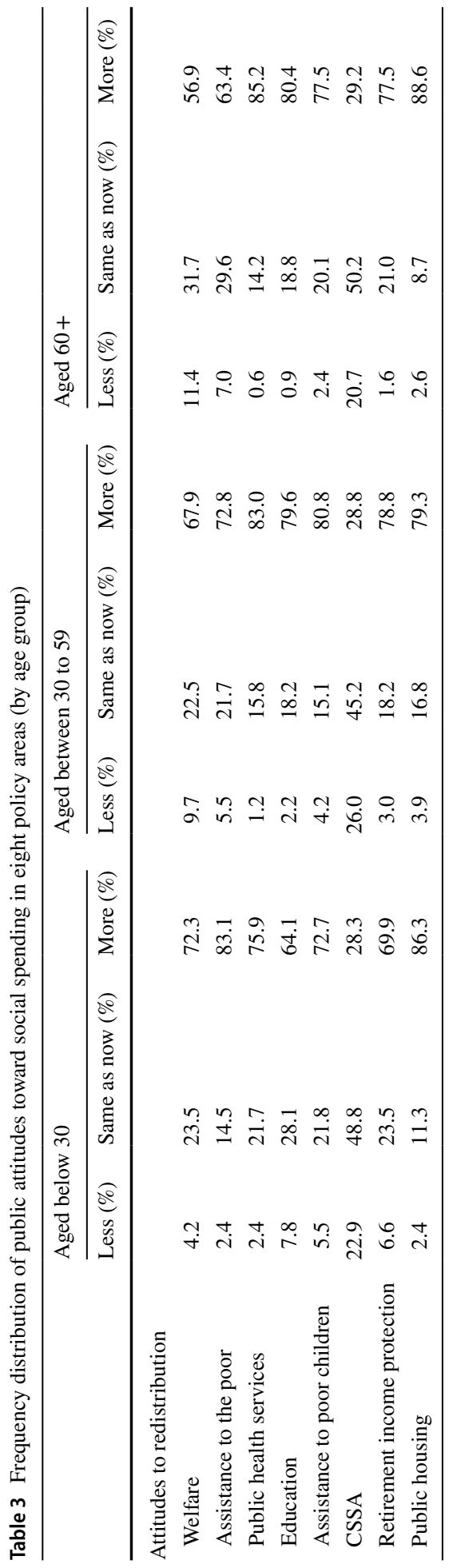


Table 4 Descriptive statistics of independent variables

\begin{tabular}{|c|c|c|}
\hline Independent variables & $\mathrm{N}$ & Percentage/Mean (SD) \\
\hline Age and labor force status & 1024 & \\
\hline$<30$ and in work & & $9.2 \%$ \\
\hline$<30$ and in education & & $7.2 \%$ \\
\hline $30-59$ and in work & & $33.5 \%$ \\
\hline $30-59$ and out of labor force & & $11.9 \%$ \\
\hline $60+$ and in work & & $6.3 \%$ \\
\hline $60+$ and retired & & $31.8 \%$ \\
\hline \multicolumn{3}{|l|}{ Self-interest variables } \\
\hline Perceived vulnerability & 972 & \\
\hline Getting better & & $25.9 \%$ \\
\hline Same & & $63.3 \%$ \\
\hline Getting worse & & $10.8 \%$ \\
\hline Perception of being in a lower social class & 1006 & $40.1 \%$ \\
\hline Number of children & 1008 & \\
\hline 0 & & $30.0 \%$ \\
\hline 1 & & $19.2 \%$ \\
\hline 2 & & $33.6 \%$ \\
\hline $3+$ & & $17.2 \%$ \\
\hline \multicolumn{3}{|l|}{ Social values variables } \\
\hline Perceived causes of income inequality & 999 & $3.65(1.32)$ \\
\hline Perceived magnitude of income inequality & 999 & $4.11(1.08)$ \\
\hline Perceived causes of poverty & 981 & \\
\hline Unlucky & & $4.7 \%$ \\
\hline Laziness & & $31.8 \%$ \\
\hline Injustice & & $28.1 \%$ \\
\hline Social development & & $35.4 \%$ \\
\hline \multicolumn{3}{|l|}{ Demographic variables } \\
\hline Female & 1031 & $59.3 \%$ \\
\hline Educational attainment & 1027 & \\
\hline Elementary or below & & $21.7 \%$ \\
\hline Junior high & & $14.2 \%$ \\
\hline Senior high & & $27.3 \%$ \\
\hline Certificate or associate degree & & $12.2 \%$ \\
\hline Bachelor degree & & $20.7 \%$ \\
\hline Postgraduate degree & & $3.9 \%$ \\
\hline Married & 1025 & $68.1 \%$ \\
\hline
\end{tabular}

perceived magnitude of income inequality exhibited a high level of agreement with the item "The differences in income in Hong Kong are too large." This reflects the severity of income inequality and poverty and the need for change in society in Hong Kong. 


\subsection{Multivariate Regression Analyses}

Table 5 shows the results of multivariate regression analyses. In terms of the dependent variable, we recoded "less spending" and "the same as now" as 1 and "more spending" as 0 . The working population aged 60 and above preferred reduced spending or maintaining the same level of spending on welfare in a general sense. With regard to assistance to the poor, those aged below 30 and out of the labor force tended to support more spending in this area; those workers aged above 60 favored less or the same level of spending. On public health services, respondents aged 30 and above preferred increased spending regardless of their employment status, while younger respondents chose less or the same level of spending. It should be noted that there were no significant effects in this model. With regard to education spending, the findings are counterintuitive. Those aged 30 and below preferred less or the same level of spending on education. People aged 30-59 and out of the labor force supported higher spending on education. These more sophisticated middleaged adults likely understand the importance of education and therefore supported such spending.

Table 6 shows that the respondents generally supported higher government spending on public housing. For example, the unemployed aged 30 or below and people aged over 60 and out of the labor force both supported increased spending in this area. As they were not employed, their financial situations and/or living conditions determined that they favored public housing. As shown in Tables 2, 3, among the eight policy areas, increased investment in public housing received the highest support. It indicates the seriousness of the housing issue in Hong Kong. Retirement income protection gained the greatest support among 30-59-year-olds who were out of the labor force. This suggests considerations of self-interest. As expected, CSSA received less support relative to other social expenditures. There are no statistically significant associations between age and labor market status and support for CSSA.

The situation became more complicated when we included both age and labor market status in our models. Employment status, whether or not one is in work, affects public attitudes toward state assistance. For example, middle-aged adults (30-59) tended to support more spending on education if they were out of the labor force. Perhaps more importantly, this group of people was inclined to support retirement income protection against the backdrop of a huge controversy with regard to this policy in Hong Kong. This suggests that the welfare state literature works to explain the demand from this group, as their weak position in the labor market is likely related to their educational attainments.

As shown in Tables 7 and 8, we included age and labor force status and three groups of independent variables in the models. In model 1, only those aged 60 above and in work tended to support less or the same level of spending on welfare. Older working adults appeared to be less willing to rely on government assistance. In model 2, the same respondents supported reducing spending (or on the same level) on assistance to the poor. The above findings are consistent with those in the models without the three groups of independent variables related to self-interest and the social values hypotheses. Model 2 also suggests that those who agreed with the statement that "inequality continues to exist because it benefits the rich and the powerful" preferred increased spending on assistance for the poor. This reveals that the social values hypothesis is at work. People who showed 


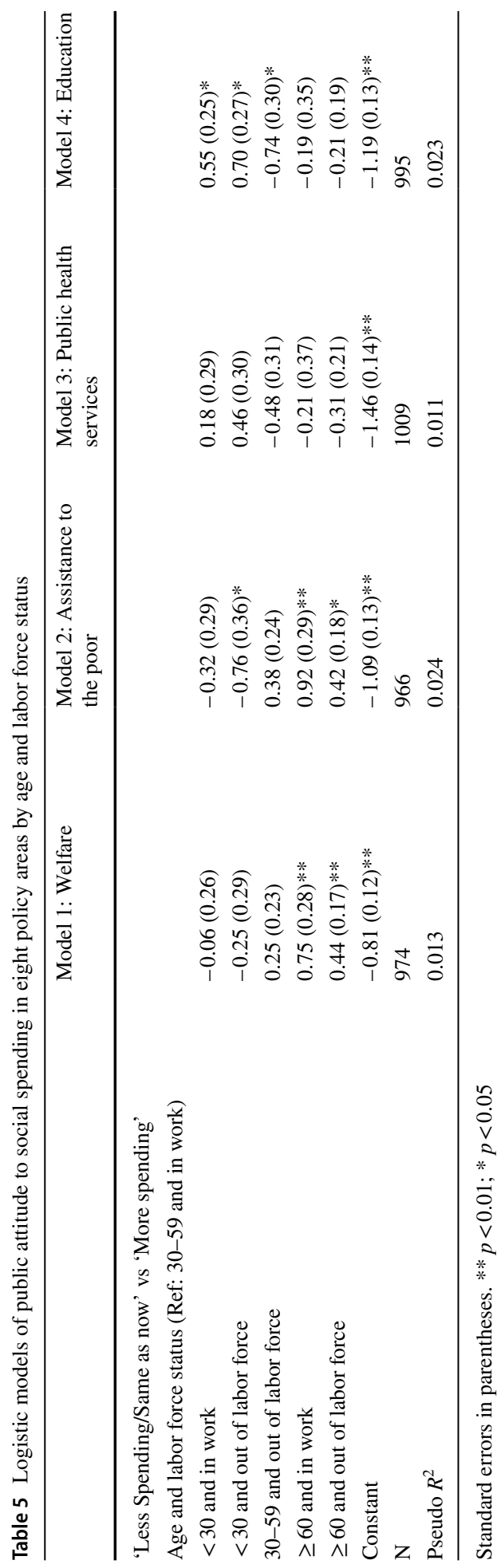




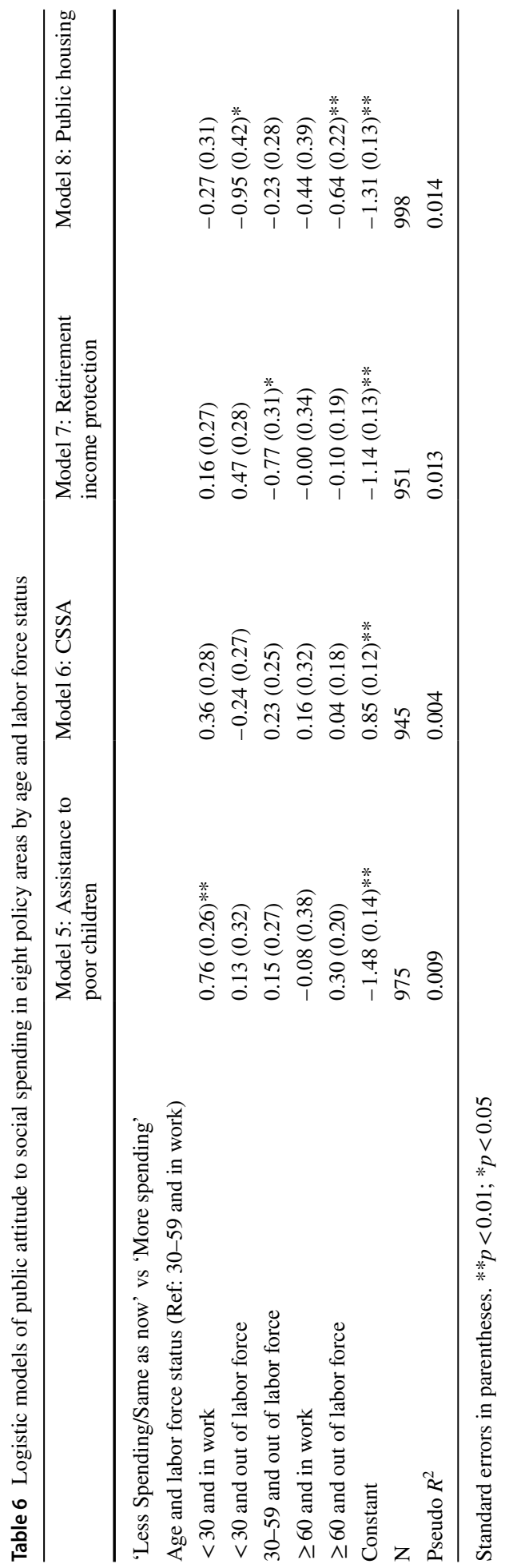




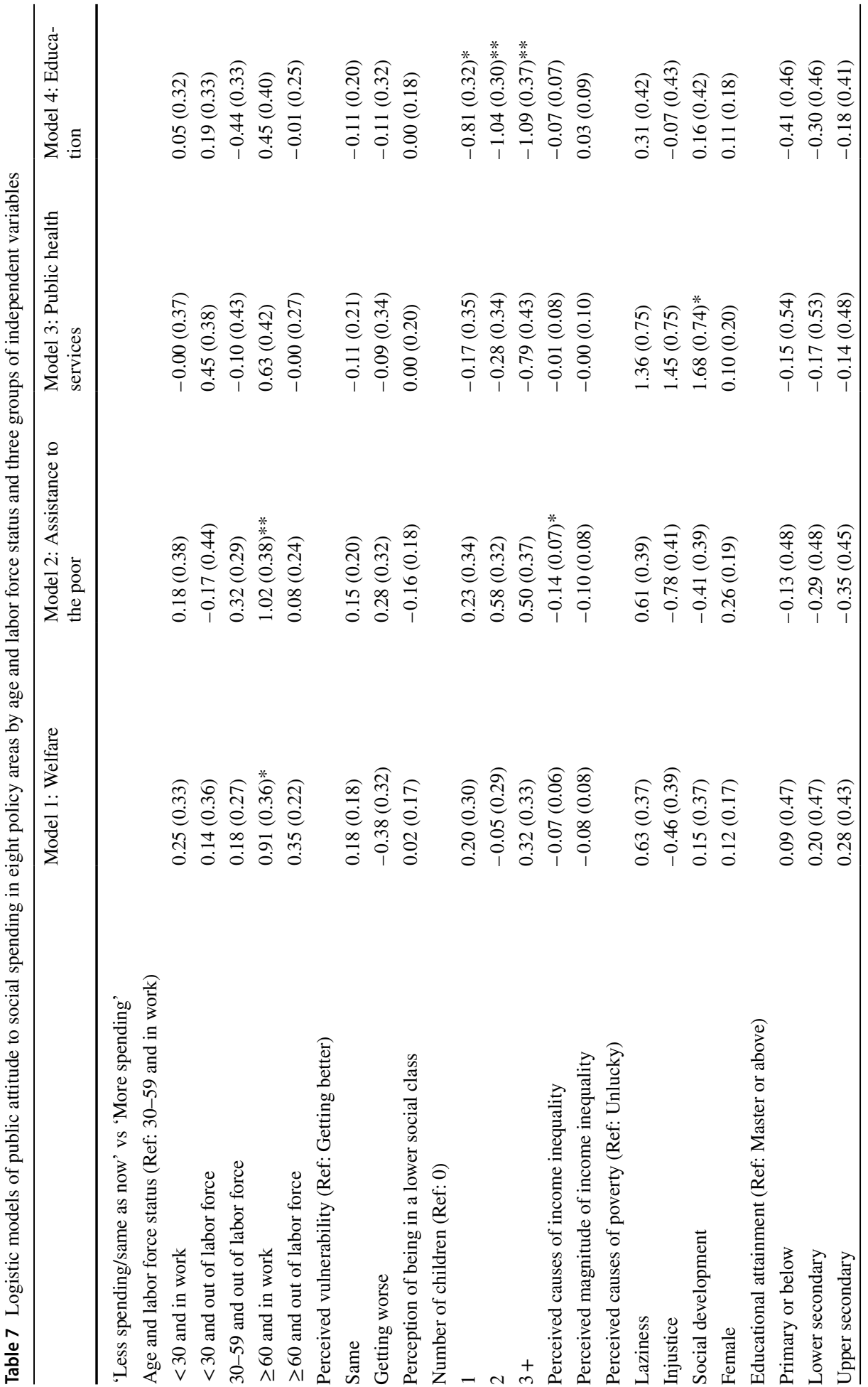




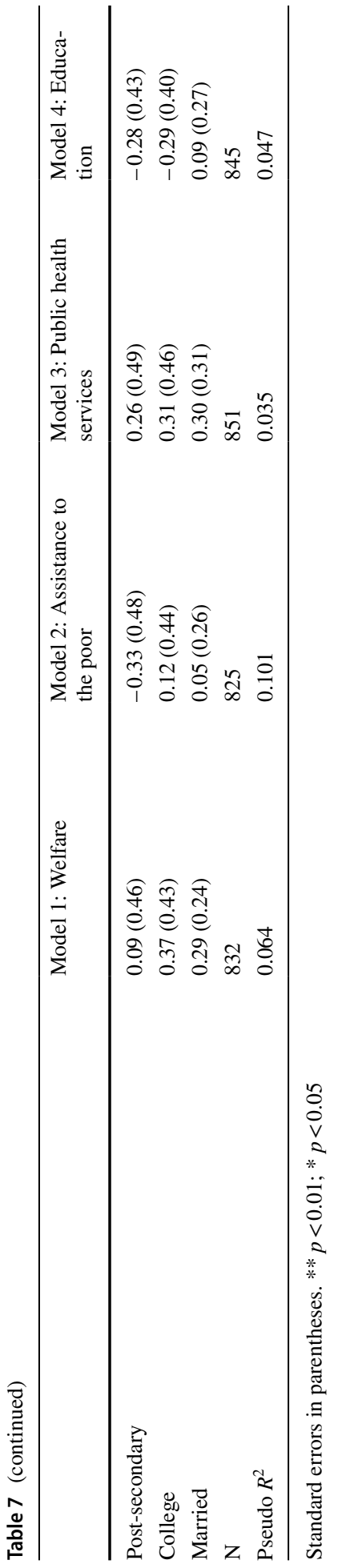




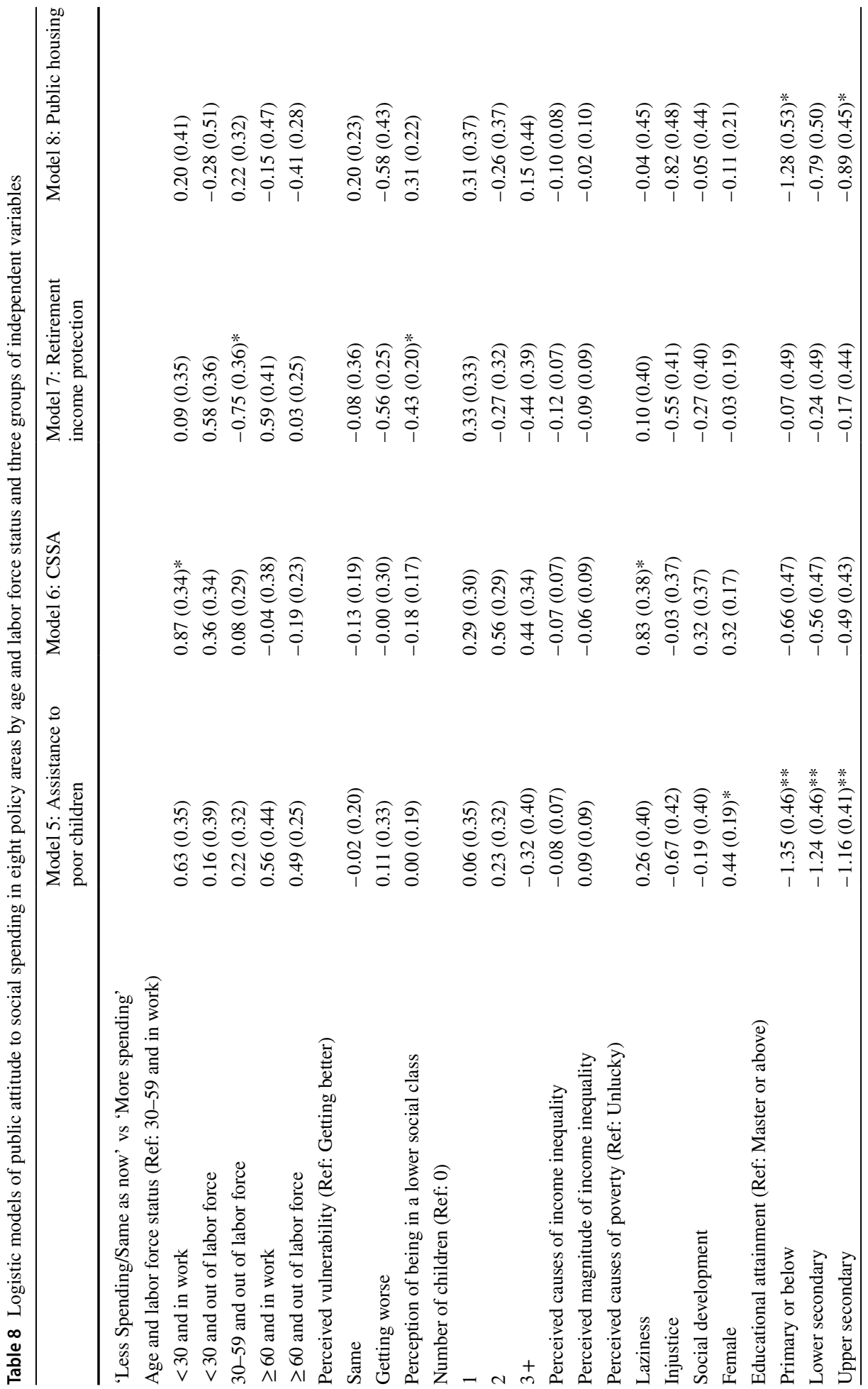




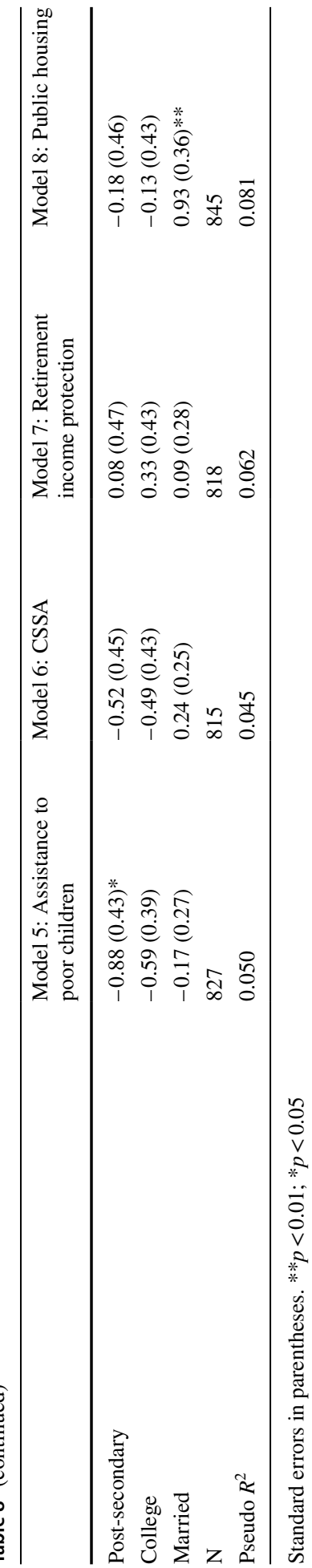


themselves to be sensitive to inequality tended to support increased spending on state assistance to the poor. In model 3, the perception of social development as the cause of poverty is significantly and positively associated with agreeing with less or the same level of spending on public health services. In model 4, those raising children tended to support more spending on education. Other factors were not statistically significant. This model does not suggest that the elderly opposed education spending.

Table 8 shows that in model 5, respondents with education below college or university level preferred spending more on assistance to poor children. This might be simply due to sympathy for poor children as the respondents suffered from a lack of education in the past. In model 6, intriguingly, those who considered laziness to be the cause of poverty tended not to support more spending on CSSA. As noted previously, CSSA was less appreciated by the respondents in our sample. According to Wong and Lou (2010), some people in Hong Kong have a stereotypical view of CSSA recipients as being lazy and lacking willpower. In model 7, those aged 30-59 and out of the labor force supported spending on retirement income protection. This demonstrates that considerations of self-interest are at play. Again, elderly status did not exert an influence on attitudes toward retirement income protection. The perception of being in a lower social class was significantly associated with support for more spending on retirement income protection. In model 8, those with lower educational qualifications supported increased spending on public housing. As noted previously, the general public would like the government to invest in more public housing projects. Those with high educational attainments usually earn a good salary, and so public housing projects are not likely to benefit them directly. By contrast, people with less education are more likely to receive public housing.

In some policy areas, the regressions, including more independent variables, such as perceived causes of poverty, suggested age-related differences. For example, with regard to retirement income protection, people aged 30-59 and out of the labor force displayed a significant negative correlation with the policy on retirees' well-being. The middle-aged unemployed were likely to support increased spending on retirement income protection. Regarding CSSA, employed young people under 30 tended to oppose increased spending in this area. Being in work and older than 60 increased the likelihood of opposing increased spending on welfare and assistance for the poor, suggesting that such people embrace an ideology of self-reliance. ${ }^{14}$

Furthermore, we implemented supplementary analyses separating the effects of age and employment status. The effect of employment status was not statistically significant for all models. The age effect was observed consistently in some policy areas.

\section{Discussion}

Our results about age-related differences in public attitudes toward social spending show that an age cleavage is present in the Hong Kong context. In the meantime, intergenerational solidarity also exists. Older employed adults tend to support less spending or keep the same level of welfare and assistance to the poor (including poor children) and support more spending on public housing. Those aged 30-59 and out of the labor force were

\footnotetext{
${ }^{14}$ Gender differences in public attitudes toward social spending are worth exploring in the future (Yu et al. 2015).
} 
inclined to support more spending on retirement income protection. People younger than 30 years old and in work tended to oppose CSSA. Supplementary analyses separating the effects of age and employment status also revealed that older adults, in general, support less or same level of spending on welfare.

The results indicate certain patterns of age-related differences in public spending preferences in an Asian context that are distinct from those seen in the Western world. Older people tend not to support increased welfare in general and government assistance to the poor in particular. The elderly are supposed to benefit more from welfare programs in general as a substantial amount of poor people in Hong Kong are older adults (Lee and Chou 2016); nonetheless, they are not supportive of welfare spending. We argue that the older generations, many of them perhaps being political and economic migrants from Mainland China, have worked hard and valued personal efforts during the economic take-off in Hong Kong. Furthermore, the older generations in Hong Kong have shown different attitudes toward many political and economic issues compared with the younger generations. Age matters, but experience does as well. In the economic take-off period, the working population might have developed similar personality traits and characteristics as a result of their similar experiences (this could be observed in different contexts such as Hong Kong and Singapore ${ }^{15}$ ). Many of them tend to support the self-reliance ideology, which has significant policy implications.

Those holding self-reliance as a virtue are likely to be less supportive of distributive and redistributive programs, wherein hardworking and capable people contribute more to government coffers while others benefit from redistribution. The redistributive nature of some welfare programs runs counter to the philosophy held by some older people in Hong Kong. Young people are articulated in welfare preferences, although the data do not deliver a coherent picture of their preferences. As the younger generations are more informed, they have a better understanding of the implementation of welfare programs. CSSA, as noted previously, is disliked by many in Hong Kong as they think that it breeds laziness. As shown before, employed young people under 30 tend not to support increased spending on CSSA.

According to the existing literature on age-related differences in public attitudes toward redistribution, the older generations tend to support pension benefits and retirement income protection. It is worth noting that in the logistic regression, we found that the middle-aged unemployed (aged 30-59 and out of the labor force) demonstrated statistically significant support for increased spending in this area. However, those aged over 60, irrespective of whether they are in work or out of the labor force, did not have a statistically significant preference for increased spending on retirement income protection. This suggests some complex demographic changes and politico-economic transitions in Hong Kong.

Conventional wisdom suggests that the elderly oppose increased spending on education (Busemeyer et al. 2009; Goerres and Tepe 2010). Nevertheless, our study in Hong Kong suggests a different pattern. As Busemeyer et al. (2009) note, in Anglo-Saxon welfare states with a minimal supply of welfare programs, an age cleavage plays a significant role. Nevertheless, our logistic regression results indicate a complicated picture. We find some sort of intergenerational solidarity. The descriptive data analysis shows that many older respondents supported increased spending on education. About $80.4 \%$ of our respondents aged 60 and above supported increased spending on education, while only $64.1 \%$ of

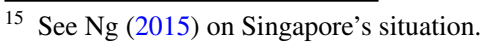


the young respondents (aged 30 years or below) favored increased spending in this area. This may suggest that intergenerational exchange and reciprocity exist in the Hong Kong society. ${ }^{16}$

Employment status differences seem to work in the Hong Kong context as well. As the unemployment rate has been relatively low (roughly lower than 5 percent over the past decade in Hong Kong) compared with other developed economies, the portion of the population out of the labor force seems insignificant. Nevertheless, Hong Kong's situation (low unemployment and relatively low labor force participation including older adults) differs from the main categories such as encompassing welfare states with low unemployment and high labor-market participation, corporatist countries with higher unemployment and the relatively lower rate of labor force participation, and Anglo-Saxon countries with high unemployment and modest labor market participation (Svallfors 1997). Therefore, the relationships between employment status and attitudes toward redistribution tend to be complex in reality. This also reflects the nuanced interaction between existing politicoeconomic conditions and public opinions about social spending. A caveat is in order. Our supplementary analyses through separating the effects of age and employment status suggest that the impact of employment status is not statistically significant in all the models.

In addition to age-related differences in social spending preference, our study confirms both the self-interest and social values hypotheses in the Hong Kong context. Some empirical results show self-interest considerations: for example, families with children tend to support increased spending on education. Social values are at work in certain scenarios: those who view income inequality as a structural problem in society tend to support increased spending on state assistance for the poor; people who see laziness as the cause of poverty tend to support reduced spending or maintain current expenditures on CSSA. Therefore, the social values held by our respondents affected their preferences regarding the investment of public money in certain policy areas.

\section{Conclusion}

In an aging and economically unequal society, the investigation of age-related differences in public attitudes toward social policy is important and significant. Life experience, selfinterest, and social values are intertwined in the Hong Kong context. The age cleavage across social policy areas coexists with intergenerational solidarity in terms of distributive and redistributive policy. Middle-aged adults work and contribute to society through a number of channels, such as paying taxes. As they become older and retire, they tend to expect that the younger generations and the government will take care of their interests. At the same time, family life may make older adults realize the importance of intergenerational exchange and reciprocity. They may, therefore, support increased spending in certain policy areas that do not benefit them directly. For example, in some contexts, the elderly have been found to support increased spending on education (Goerres and Tepe 2010). Although the younger generations have less experience in social life, many young

\footnotetext{
16 This begs a new, separate research question, that is, whether implicit intra-family support, influenced by Confucianism, has any impact on public spending preferences by older people and young people (see Chen et al. 2019). This means that older people may think that the improvement of education attainments through more government spending on education may finally improve their interests through intra-family financial support between parents and children.
} 
people in Hong Kong support increased spending on welfare and assistance to the poor based on descriptive statistics, which may suggest the change of social values. In this study, reciprocity and solidarity exist in Hong Kong, which has profound implications for social policymaking in an aging society. ${ }^{17}$

In this study, we have asked which factors determine public attitudes toward social spending and welfare programs. We observe that both self-interest and social values matter in the case of Hong Kong. This means that personal circumstances, for example, raising children, will lead people to support increased public spending on education. Equally, social values, such as considering poverty to be a result of structural factors rather than personal failings, tend to lead people to endorse increased spending on helping the poor.

More importantly, we have attempted to understand the impact of age on spending preferences. ${ }^{18}$ We find that age matters in public attitudes toward social policy, but the signs of solidarity are also attested to in the Hong Kong context. Our study shows patterns that differ from the findings in Western contexts. For example, older people usually favor benefits associated with retirement. In this study, the relationship between older adults and support for retirement income protection was not found to be statistically significant. Older people also favor reducing spending (or maintaining the same level of spending) on welfare in general and assistance for the poor. As the chances of living in poverty in later life are relatively high in many developed economies, including Hong Kong, this finding is somewhat counterintuitive. It begs the question to be answered in the future. It may be due to a variety of reasons. Particularly the older generations, who contributed substantially during the period of economic take-off in Hong Kong, value self-reliance. They behave altruistically; however, it does not mean that retirement income protection, which benefits older people, could be compromised due to the current inconclusive result.

Our results bring to the fore the age-related differences in public attitudes toward social spending in a small, dynamic (to some extent, fragile) Asian economy. This study did not find "elderly power" at play in the Hong Kong context. To some extent, the elderly show altruism toward other segments of society. The younger generations also show sympathy toward the poor and agree with more spending on the poor (but not spending related to CSSA). The government should shore up social investments that benefit older people. ${ }^{19}$ These social investments could not only consist of benefits helping them lead a decent later life but also public programs enhancing their quality of life and happiness, including such social policies as an elderly-friendly employment policy. Some spending on elderlyspecific programs can strengthen family solidarity and lay strong foundations for a sound social policy in Hong Kong to support economic growth and address social ills related to poverty and income inequality. As we have noted, since the younger generations in Hong Kong tend to be more willing to help and support the poor in their society, spending on the elderly would not lead to intergenerational blame; it would give young people a chance to learn social responsibility through an intergenerational exchange. For the younger

\footnotetext{
17 Drawing on cross-country evidence, Wang et al. (2021) note that, understanding social values is crucial for policymaking around the world.

18 Intriguingly, the study on the relationship between age and subjective well-being also suggests a life cycle pattern with people aged above 65 reporting the highest subjective well-being in the Chinese context (Xing and Huang 2014).

19 Fung (2014) pointed out that the welfare regime in Hong Kong has accorded less attention to "nonproductive" groups.
} 
generations, given their positive attitudes toward some social policy areas, it suggests a friendly policy environment for improving distributive and redistributive policy such as education, public housing, and assistance to the poor. However, we have not established whether younger generations develop self-interest or keep their social values constant as they age. The dynamics of age-related differences in public attitudes toward social spending will shed light on the debate in many other contexts in Asia and beyond.

Supplementary Information The online version contains supplementary material available at https://doi. org/10.1007/s11205-021-02607-9.

Funding Support for this research was provided by the Research Grant Council Public Policy Research Fund (HKIEd 7005-PPR-12) and Start-up Research Grant at The Education University of Hong Kong (formerly The Hong Kong Institute of Education) (RG 86/201202913R).

Open Access This article is licensed under a Creative Commons Attribution 4.0 International License, which permits use, sharing, adaptation, distribution and reproduction in any medium or format, as long as you give appropriate credit to the original author(s) and the source, provide a link to the Creative Commons licence, and indicate if changes were made. The images or other third party material in this article are included in the article's Creative Commons licence, unless indicated otherwise in a credit line to the material. If material is not included in the article's Creative Commons licence and your intended use is not permitted by statutory regulation or exceeds the permitted use, you will need to obtain permission directly from the copyright holder. To view a copy of this licence, visit http://creativecommons.org/licenses/by/4.0/.

\section{References}

Becker, G. S. (1981). Altruism in the family and selfishness in the market place. Economica, 48(189), 1-15.

Blekesaune, M., \& Quadagno, J. (2003). Public attitudes toward welfare state policies a comparative analysis of 24 nations. European Sociological Review, 19(5), 415-427.

Busemeyer, M. R., Goerres, A., \& Weschle, S. (2009). Attitudes towards redistributive spending in an era of demographic ageing: The rival pressures from age and income in 14 OECD countries. Journal of European Social Policy, 19(3), 195-212.

Chan, C. A., \& Liang, J. E. (2013). Active aging: Policy framework and applications to promote older adult participation in Hong Kong. Ageing International, 38(1), 28-42.

Chan, L., \& Chou, K. (2016). Immigration, living arrangement and the poverty risk of older adults in Hong Kong. International Journal of Social Welfare, 25(3), 247-258.

Chan, L., \& Chou, K. (2018). A survey of asset poverty among older adults of Hong Kong. Social Indicators Research, 138(2), 605-622.

Chen, Y. J., Chen, Z., \& He, S. (2019). Social norms and household savings rates in China. Review of Finance, 23(5), 961-991.

Chou, K., \& Chow, N. W. (2005). Income inequality among older adults in Hong Kong: An analysis of change from 1981 to 2001. Journal of Applied Gerontology, 24(5), 388-403.

Chou, K., Yu, K., Chan, W., Wu, A. M., Zhu, A. Y., \& Lou, V. W. (2015). Perceived retirement savings adequacy in Hong Kong: An interdisciplinary financial planning model. Ageing and Society, 35(8), 1565-1586.

Chui, E., \& Ko, L. (2010). Elderly poverty and old-age pension reform in Hong Kong: Issues and prospects. In K. H. Mok \& Y. Ku (Eds.), Social cohesion in greater China: Challenges for social policy and governance (pp. 253-285). Singapore: World Scientific.

Commission on Poverty. (2015). Retirement protection forging ahead: Consultation Document. Hong Kong, China: Hong Kong SAR Government Printer.

Daatland, S. O., Veenstra, M., \& Herlofson, K. (2012). Age and intergenerational attitudes in the family and the welfare state. Advances in Life Course Research, 17(3), 133-144.

Dorey, P. (2010). A poverty of imagination: Blaming the poor for inequality. The Political Quarterly, 81(3), 333-343.

Feldman, S., \& Steenbergen, M. R. (2001). The humanitarian foundation of public support for social welfare. American Journal of Political Science, 45(3), 658-677.

Fong, C. (2001). Social preferences, self-interest, and the demand for redistribution. Journal of Public Economics, 82(2), 225-246. 
Funk, C. L. (2000). The dual influence of self-interest and societal interest in public opinion. Political Research Quarterly, 53(1), 37-62.

Fung, K. K. (2014). Financial crisis and the developmental states: A case study of Hong Kong. International Journal of Social Welfare, 23(3), 321-332.

Goerres, A., \& Tepe, M. (2010). Age-based self-interest, intergenerational solidarity and the welfare state: A comparative analysis of older people's attitudes towards public childcare in 12 OECD countries. European Journal of Political Research, 49(6), 818-851.

Goerres, A., \& Vanhuysse, P. (2012). Mapping the field: Comparative generational politics and policies in ageing democracies. In P. Vanhuysse \& A. Goerres (Eds.), Ageing populations in post-industrial democracies: Comparative studies of policies and politics (pp. 1-22). Abingdon: Routledge.

Jæger, M. M. (2006). What makes people support public responsibility for welfare provision: Self-interest or political ideology? A longitudinal approach. Acta Sociologica, 49(3), 321-338.

Kulig, J. C., Edge, D. S., Townshend, I., Lightfoot, N., \& Reimer, W. (2013). Community resiliency: Emerging theoretical insights. Journal of Community Psychology, 41(6), 758-775.

Lee, S., \& Chou, K. (2016). Trends in elderly poverty in Hong Kong: A decomposition analysis. Social Indicators Research, 129(2), 551-564.

McCall, L., \& Kenworthy, L. (2009). Americans' social policy preferences in the era of rising inequality. Perspectives on Politics, 7(03), 459-484.

Menz, G. (2015). Whatever happened to social Europe? The three-pronged attack on European social policy. In A. Crespy \& G. Menz (Eds.), Social policy and the Euro crisis (pp. 45-62). London: Palgrave Macmillan.

$\mathrm{Ng}$, I. Y. (2015). Being poor in a rich "nanny state": Developments in Singapore social welfare. The Singapore Economic Review, 60(3), 1-17.

Organisation for Economic Co-operation and Development. (1998). Maintaining prosperity in an ageing society.Paris: OECD.

Tang, K. (2000). Social welfare development in East Asia. Basingstoke England: Palgrave.

Svallfors, S. (2004). Class, attitudes and the welfare state: Sweden in comparative perspective. Social Policy \& Administration, 38(2), 119-138.

Svallfors, S. (1997). Worlds of welfare and attitudes to redistribution: A comparison of eight Western nations. European Sociological Review, 13(3), 283-304.

United Nations Development Programme. (2010). Human development report 2010: The real wealth of nations: Pathways to human development. Palgrave Macmillan.

Wang, B., Xia, L., \& Wu, A. M. (2021). Social development with public value: An international comparison. Social Indicators Research.

Wong, C., \& Lou, V. W. (2010). "I wish to be self-reliant": Aspiration for self-reliance, need and life satisfaction, and exit dilemma of welfare recipients in Hong Kong. Social Indicators Research, 95(3), 519-534.

Wu, A. M., \& Chou, K. (2017). Public attitudes towards income redistribution: Evidence from Hong Kong. Social Policy \& Administration, 51(5), 738-754.

Xing, Z., \& Huang, L. (2014). The relationship between age and subjective well-being: Evidence from five capital cities in mainland China. Social Indicators Research, 117(3), 743-756.

Yang, S., Miao, B., \& Wu, A. M. (2020). Immigration and public attitudes towards social assistance: Evidence from Hong Kong. Journal of Economic Policy Reform.

Yu, K., Wu, A. M., Chan, W., \& Chou, K. (2015). Gender differences in financial literacy among Hong Kong workers. Educational Gerontology, 41(4), 315-326.

Publisher's Note Springer Nature remains neutral with regard to jurisdictional claims in published maps and institutional affiliations. 